\title{
Magnetic Nitrogen-doped graphene synthesized from orange peel as highly effective adsorbent for removal of sodium dodecyl benzenesulfonate (SDBS) from aqueous solutions
}

Arash Khoshnoodfar ( $\square$ arash.khoshnoodfar69@gmail.com )

Tarbiat Modares University

Nader Bahramifar

Tarbiat Modares University

Habibollah Younesi

Tarbiat Modares University

\section{Research Article}

Keywords: SDBS, magnetic Nitrogen doped graphene, adsorption capacity, adsorbent, water and wastewater treatment.

Posted Date: April 19th, 2021

DOI: https://doi.org/10.21203/rs.3.rs-391533/v1

License: () (1) This work is licensed under a Creative Commons Attribution 4.0 International License. Read Full License 


\section{Abstract}

The purpose of the current research is to investigate the adsorption process behavior of magnetic nitrogen doped graphene (MNG) prepared from the orange peel in the adsorption of sodium dodecylbenzene sulfonate (SDBS) from liquid solution in batch experiments. The characteristics results of VSM, FTIR, SEM, AFM, Raman, elemental analysis and BET surface area analysis revealed the successful synthesis nano adsorbent. The effective factors on adsorption performance were including adsorbent dosage, temperature, contact time, $\mathrm{pH}$ and initial concentration of SDBS. The Maximum adsorption capacity for SDBS is computed to be $556 \mathrm{mg} / \mathrm{g}$ at $45^{\circ} \mathrm{C}$ and $\mathrm{pH}$ of 3 . The adsorption process of SDBS was found that fitted well with the Langmuir isotherm model and pseudo-second-order kinetic equations. Thermodynamic analysis proved the spontaneous and endothermic nature of the adsorption process. Furthermore, the SDBS can be desorbed from the fabricated nano adsorbent by methanol solution with $88 \%$ desorption efficiency and MNG indicated good reusability after five cycles. The finding from this research, propose that the as-synthesized MNG could be an effective adsorbent for water and wastewater treatment because of its convenient process and magnetic separation.

\section{Introduction}

Sodium dodecylbenzene sulfonate (SDBS) is a high content anionic surfactant with detergency, moistening and foaming properties which is widely used in household detergents, fiber industry, metal plating processes, leather industry, paper industry, agricultural chemicals (Li et al. 2020). The mean concentration of SDBS in urban wastewaters reported between 1-10 mg/L, while its mean concentrations for industrial wastewaters were above $300 \mathrm{mg} / \mathrm{L}$ (Leyva-Ramos et al. 2020). SDBS mainly considered as one of the most important hazards to the aquatic life and soil, and discharges these chemical compounds into the environment can make serious environmental problems through eutrophication, foam generation and reduce in dissolved oxygen of the receiving water (Nazari and Ayati 2019). The removal of SDBS from wastewaters is an effortful work and needs long time in wastewater treatment plants. So far, many conventional treatment methods have been employed to reduce surfactants from domestic and industrial wastewaters that these methods contain physical, chemical, biological treatments, coagulation and filtration, ion exchange. Since these methods are generally costly, produce some detrimental by products, lack of selectivity, need complicated instruments and time consuming; thus cannot be effectively utilized in environmental treatments. Therefore, it is necessary to apply a candidate approach that is capable to effectively remove or decrease the detergents from aqueous environment. Among treatment methods, adsorption process has recently been recognized to be as potential alternatives in environmental monitoring owing to its simpleness of design, great selectivity and low production volume of waste, cost-effectiveness of operation (Wu et al. 2015). In this regard, some porous adsorbents including chitosan (Parhizgar et al. 2017), polymer adsorbents (Garcia-Delgado et al. 1992), activated carbon (Zhang et al. 2009), zeolites (Taffarel and Rubio 2010), metal oxide (Méndez-Díaz et al. 2009) and multi-walled carbon nanotubes (Tan et al. 2008) was employed for SDBS removal from water and wastewater. Today, graphene has attracted a high deal of attention in the field of adsorbing material owing to their unique physicomechanical features including huge surface area, significant electrical conductivity, desirable chemical stability, fast charged carrier mobility and optical transparency (Singh et al. 2018). Numerous procedures have been provided to further modify and develop the physicomechanical and electronic features of graphene including chemical functionalization, graphene hybrid, electrochemical modification and chemical doping with foreign atoms like boron (B), nitrogen (N), oxygen (O), sulfur (S), etc (Wang et al. 2012a). By doing this, chemical doping seems to 
be as an effective method to improve the electrical conductivity properties and chemical reactivity of graphene (Wang et al. 2010). Nitrogen consist of five valence electrons available for bonding with carbon atoms, and so is regarded to be an element of highly effective for the chemical doping processes of materials (Li et al. 2016). It was well found that the N-doped graphene (NG) displayed predominant performance compared to bare graphene due to its the greater surface area to volume ratio and higher electrical conductivity (Yang et al. 2013, Jiang et al. 2014). Beside, N-doped graphene possess chemically further active sites to capture of SDBS and other pollutants through enter of nitrogen atoms into graphene carbon lattices and hence, nitrogen doping process is of excellent potential to be applied for graphene modification. Several studies have also been made for employing N-doped graphene as a good adsorbent for use in water treatment process (Wang et al. 2012b, Wang et al. 2014). However, the separation of N-doped graphene from the aqueous phase owing to its small particle size seem very difficult. Thus, the fabrication of magnetic complexes with $\mathrm{N}$-doped graphene causes the separation easier and swiftly from the aqueous phase at the final of the adsorption process. In various studies, researchers have distributed $\mathrm{Fe}_{3} \mathrm{O}_{4}$ magnetic nanoparticles onto the graphene sheet surfaces to obtain magnetic graphene-based materials (Yang et al. 2009, Yang et al. 2014). In the present research, we produced for the first time magnetic N-doped graphene from orange peel as precursor and utilized it for adsorption of SDBS from liquid solution in batch experiments. A characteristic privilege of this method other than that conventional methods is the high mesoporosity and large surface area to volume ratio of synthesized magnetic nanoparticle through chemical $N$-doping that would cause possible the removal of SDBS from contaminated water. The influence of the different parameters such as solution $\mathrm{pH}$, adsorbent dosage, initial concentration of SDBS, temperature and contact time were investigated. The thermodynamic characteristics, including Gibbs free energy, enthalpy and entropy of the adsorption were examined. Besides, the archived data were described with the Langmuir, Freundlich, and Redlich Peter- son isotherm models.

\section{Experimental}

\subsection{Chemicals}

In this research, orange peel, was utilized as a good precursor material for the preparation of MNG in SDBS adsorption process. The material firstly was grinded and then sieved to pass by $60 \mu \mathrm{m}$ mesh to get an uniform particle size. Afterward, they washed completely with distilled water for eliminating impurities residues and finally dried in an oven at $70{ }^{\circ} \mathrm{C}$ for $48 \mathrm{~h}$ to until permanent weight was attained.

With the aim to the preparation and synthesis of MNG, the following chemicals were utilized: Sodium dodecylbenzene sulfonate $\left(\mathrm{C}_{18} \mathrm{H}_{29} \mathrm{SO}_{3} \mathrm{Na}\right)$ was prepared from Acros, America and Potassium hydroxide (KOH) was provided from Scharlo, Spain. Sodium hydroxide, sulfuric acid, hydrochloric acid (37\%), methanol, ethanol, sodium acetate $(\mathrm{NaAc})$, ferric chloride hexahydrate $\left(\mathrm{FeCl}_{3} \cdot 6 \mathrm{H}_{2} \mathrm{O}\right)$, ethylene glycol $(\mathrm{EG})$ and urea $(\mathrm{CH} \otimes \mathrm{N} \otimes \mathrm{O})$ were purchased from Merck, Germany. Further, deionized water $\left(E C=0.055 \mu \mathrm{S} \mathrm{m}{ }^{-1}\right)$, was applied overall the experiments.

\subsection{N-doped graphene synthesis}

For synthesizing of N-doped graphene were used waste orange peel as carbon source and urea as nitrogen source. At first, $5 \mathrm{~g}$ of carbonized sample was mixed with $15 \mathrm{~g}$ urea based on the ratio of 3:1 on a magnetic stirrer at room temperature for $1 \mathrm{~h}$. After blending, it was dried in an oven at $110{ }^{\circ} \mathrm{C}$ for $48 \mathrm{~h}$. Then, the mixture 
was placed in a ceramic boat into the quartz tube model (Nabertherm RS 80/750/11, Germany) under argon gas flow outside the furnace with a heating rate of $5^{\circ} \mathrm{C} \mathrm{min}-1$, which reached $700{ }^{\circ} \mathrm{C}$, and then it was preserved at this temperature for $1 \mathrm{~h}$. After the reaction finished, the sample was cooled to room temperature under argon gas overnight and was removed from the reactor at the finale of each experiment. In the next step, $5 \mathrm{~g}$ of the synthesized sample was stirred with $25 \mathrm{~g} \mathrm{KOH}$ in ratios of $1: 5$ and was dried in an oven at $110{ }^{\circ} \mathrm{C}$ for $48 \mathrm{~h}$. The sample was heated in a ceramic furnace under argon gas flow with a heating rate of $10{ }^{\circ} \mathrm{C} \mathrm{min}^{-1}$, which approached $900^{\circ} \mathrm{C}$, and then it was preserved at this temperature for $2 \mathrm{~h}$. After the step, the samples were cooled in an argon gas and removed from the reactor at the final of each experiment. Later, the sample was mixed with $0.1 \mathrm{M} \mathrm{HCl}$ for $3 \mathrm{~h}$ on a magnetic stirrer to remove the potassium hydroxide compounds. Finally, the prepared sample was filtered and was then repeatedly washed with deionized until the pH attained 6-7 and dried in an oven at $110^{\circ} \mathrm{C}$ for $12 \mathrm{~h}$ (Muramatsu et al. 2014).

\subsection{Magnetic $N$-doped graphene synthesis}

The $\mathrm{Fe}_{3} \mathrm{O}_{4}-\mathrm{G}$ nanoparticles preparation was performed according to the hydrothermal method. Briefly, $0.5 \mathrm{~g}$ of $\mathrm{N}$-doped graphene (NG) powder was ultrasonicated in $70 \mathrm{ml}$ ethylene glycol C for $3 \mathrm{~h}$. Then, $0.5 \mathrm{~g} \mathrm{of} \mathrm{FeCl}_{3} \cdot 6 \mathrm{H}_{2} \mathrm{O}$ and $1 \mathrm{~g}$ of sodium acetate ( $\mathrm{NaAc}$ ) was added to the above mixture for $30 \mathrm{~min}$. The mixture was placed into a Teflon-lined stainless-steel autoclave and thereafter heated at $200{ }^{\circ} \mathrm{C}$ for $10 \mathrm{~h}$ and then cooled at ambient temperature. Finally, the obtained nanocomposite several times was completely washed with distilled water and ethanol and vacuum dried at $-60{ }^{\circ} \mathrm{C}$ for $6 \mathrm{~h}$ (Ai et al. 2011).

\subsection{Characterization}

Earlier performing the adsorption experiments, the as-synthesized nanoparticles were determined by AFM, SEM, BET, FTIR, Raman, VSM and elemental analysis (CHNS) as expressed in the following description. The Raman spectroscopy analyses of the samples were recorded by using a Raman Spectrometer model (Thermo Scientific DXR, USA) in the spectral range of $200-4500 \mathrm{~cm}^{-1}$. The atomic force microscopy (AFM) image was utilized employing a Park Scientific CP-Research model (VEECO) to investigate the thickness of N-doped graphene sheets. The qualitative measurements for identifying functional groups by FTIR were performed with a Shimadzu FT-IR 8400 spectrometer (Japan) using KBr as a background over the range of $4000-400 \mathrm{~cm}^{-1}$. The scanning electron microscopy (SEM.LEO 1455VP microscope, Cambridge, U.K) was investigated to observe the size and morphology of the nanocomposites. Brunauer-Emmett-Teller (BET) analysis was utilized for calculating the specific surface area and the pore size distribution with a Micromeritics ASAP 2010, system (Japan). The vibrating sample magnetometer analysis (VSM) (Meghnatis Daghigh Kavir Co., Kashan, Iran) was examined to measure the magnetic properties of materials at room temperature. The weight percentages of elements determined by the Carbon, hydrogen, nitrogen, and sulfur (CHNS) analyses using a Thermo Finnigan Corporation Flash EA 1112 in $G$ and magnetic $N$-doped graphene.

\subsection{Batch adsorption experiments}

The adsorption studies of SDBS on MNG carried out applying the batch equilibrium procedure in a set of 150 $\mathrm{mL}$ Erlenmeyer and was shaken on a shaker operated at $200 \mathrm{rpm}$ at $25^{\circ} \mathrm{C}$. In batch process, the adsorption tests were done under constant conditions, solution volume of $100 \mathrm{~mL}$, SDBS concentration of $50 \mathrm{mg} / \mathrm{L}$, an adsorbent dosage of $0.1 \mathrm{~g} / \mathrm{L}, \mathrm{pH}=3$, at a temperature of $45^{\circ} \mathrm{C}$ for $60 \mathrm{~min}$. Then, the magnetic nano adsorbent 
was removed by using a magnet and the supernatant was gathered for SDBS concentration measurement. In the batch experiments, the influences of, adsorbent dosage, contact time, initial SDBS concentration, solution $\mathrm{pH}$ and temperature on SDBS removal were studied. The solution $\mathrm{pH}$ was adjusted by adding $\mathrm{HCl}$ or $\mathrm{NaOH}$. The final concentration of SDBS was measured by UV-Vis spectrophotometer (PerkinElmer Lambda $25 \mathrm{UV} / \mathrm{Vis}$ Spectrometer) at $223 \mathrm{~nm}$. Moreover, blank samples (including only deionized water and prepared adsorbent) were provided and investigated as a control. In All experiments, the mean values with three replications were given. In the adsorption process, the performance of parameters in the removal of SDBS were studied under different conditions including nano adsorbent dose $(0.1-0.25 \mathrm{~g} / \mathrm{L})$, temperature $\left(15-45^{\circ} \mathrm{C}\right)$, contact time (5-90 min), pH (2-10) and concentration of SDBS (50-150 mg/L).

\subsection{Desorption studies}

In order to evaluate the reusability of SDBS in batch mode, optimal weighting of MNG was added to $20 \mathrm{~mL}$ of the methanol and ethanol as eluents. Afterward that, the spent nano adsorbent was separated by a magnet and washed twice with deionized water and dried at $70{ }^{\circ} \mathrm{C}$ for $60 \mathrm{~min}$, and then recycled for adsorption again. Furthermore, the reusability of nano adsorbent was experienced under the optimized conditions. The SDBS regeneration was calculated by equation 1 :

$$
\text { SDBS regeneration }=\frac{\text { Amount of SDBS desorbed }}{\text { Amount of SDBS adsorbed }} \times 100
$$

\subsection{Adsorption kinetics}

Adsorption kinetics tests were performed by mixing $100 \mathrm{~mL}$ of SDBS solution of different concentrations (50$150 \mathrm{mg} / \mathrm{L}$ ) with $0.15 \mathrm{~g} / \mathrm{L}$ of nano adsorbent and mixture were agitated at $200 \mathrm{rpm}$ at $25^{\circ} \mathrm{C}$. Adsorption kinetics studies were also investigated to examine the mechanism of adsorption of SDBS onto MNG nano composite. The Lagergren-first-order rate, the pseudo-second-order and the intra-particle diffusion model (IPD) models were utilized to evaluate the adsorption kinetics. It is essential to recommend the correlation coefficient $\left(R^{2}\right.$, close or equal to 1) to calculate the propriety of different models. Generally, the higher $R^{2}$ value exhibits a further pleasant kinetic model. The kinetic models provided in the following equation (Yuh-Shan 2004, Ho 2006):

$$
\begin{aligned}
& \log \left(q_{e}-q_{t}\right)=\log q_{e}-\frac{K_{1}}{2.303} t \\
& \frac{\mathrm{t}}{\mathrm{q}_{\mathrm{t}}}=\frac{1}{\mathrm{k}_{2} \mathrm{q}_{\mathrm{e}}^{2}}+\frac{\mathrm{t}}{\mathrm{q}_{e}}
\end{aligned}
$$

where qe and $\mathrm{q}_{\mathrm{t}}(\mathrm{mg} / \mathrm{g})$ are the amount of SDBS adsorbed at equilibrium time and amount of SDBS adsorbed at the time, respectively. $\mathrm{k}_{1}\left(\mathrm{~min}^{-1}\right)$ and $\mathrm{k}_{2}(\mathrm{~g} / \mathrm{mg}$. $\mathrm{min})$ are the rate constants.

The intra-particle diffusion model (IPD), offered by Weber has been utilized for understanding to the mechanisms and rate controlling stages influencing the adsorption kinetics. The kinetic results were examined by the intra particle diffusion model to reveal the diffusion mechanism, which can be expressed as:

$$
\mathrm{q}_{\mathrm{t}}=\mathrm{K}_{\mathrm{id}} \mathrm{t}^{1 / 2}+\mathrm{C}
$$


where $\mathrm{C}$ is the intercept $(\mathrm{mg} / \mathrm{g})$ which is correlated to the boundary layer thickness and $\mathrm{k}_{\mathrm{id}}$ is the slope which signifies the intra particle diffusion rate constant $\left(\mathrm{mg} / \mathrm{g} \mathrm{h}^{1 / 2}\right)$, which can be estimated from the slope of the linear plot of $q_{t}$ versus $t^{1 / 2}$.

\subsection{Adsorption isotherms}

To evaluate the relation between the molecules SDBS adsorbed on the prepared nano adsorbent and the concentration of SDBS remained in the liquid phase, the isotherm data were determined by the Freundlich, Langmuir and Redlich-Peterson (R-P) models.

The Langmuir isotherm is utilized to explain the behavior of the equilibrium between adsorbate and adsorbent and adsorption take place on a homogeneous surface which is limited to monolayer surface without interaction between the absorbed materials. The Langmuir model can be ascribed by equation 5 (Langmuir 1918):

$$
q_{e}=\frac{q_{m} \cdot \mathrm{bc} C_{e}}{1+b C_{e}}
$$

where $C_{e}(\mathrm{mg} / \mathrm{L})$ is the equilibrium concentration of SDBS solution, $\mathrm{q}_{e}(\mathrm{mg} / \mathrm{g})$ is the adsorption capacity at equilibrium adsorption capacity $\left(\mathrm{q}_{\mathrm{m}}\right)$ and $\mathrm{b}$ are the maximum adsorption capacity $(\mathrm{mg} / \mathrm{g})$ and the equilibrium adsorption constant $(\mathrm{L} / \mathrm{mg})$. Freundlich model is an empirical adsorption model and provide a beneficial perceptual basis for perception between SDBS concentration on the nano adsorbent surface and concentration in the aqueous phase. Also, this isotherm model was developed to ascribe equilibrium adsorption for multilayer system according to the assumption of an exponential distribution of adsorption energies for each component. The Freundlich isotherm can be written in the linear form by equation 6 (Freundlich 1907):

$$
q_{e}=K_{f} C_{e}^{1 / n}
$$

where $\mathrm{q}_{\mathrm{e}}(\mathrm{mg} / \mathrm{g})$ is the equilibrium adsorption capacity of adsorbent, $\mathrm{C}_{\mathrm{e}}(\mathrm{mg} / \mathrm{L})$ is the concentration of SDBS in liquid phase at equilibrium, $\mathrm{K}_{\mathrm{f}}\left((\mathrm{mg} / \mathrm{g})(\mathrm{l} / \mathrm{mg})^{1 / \mathrm{n}}\right)$ is Freundlich adsorption equilibrium constant and $\mathrm{n}$ is the empirical constant suggesting the intensity of adsorption which proves with the heterogeneity of adsorbent.

The Redlich-Peterson (R-P) isotherm model is widely employed for demonstrating adsorption equilibrium over a broad concentration range and can be used in both homogeneous and heterogeneous systems because of its versatility (Piccin et al. 2011). The Redlich-Peterson (R-P) model can be expressed by the following linear equation:

$$
\ln \left(q_{R P} K_{R P} \frac{c_{e}}{q_{e}}-1\right)=\ln K_{R P}+\beta \ln C_{e}
$$

where, $\mathrm{K}_{\mathrm{RP}}$ and $\beta$ are the $\mathrm{R}-\mathrm{P}$ constants and $\mathrm{q}_{\mathrm{RP}}$ show the adsorption capacity in $\mathrm{mg} / \mathrm{g}$.

\subsection{Adsorption thermodynamics}


The thermodynamic studies are investigated through the calculation of standard Gibbs free energy changes $\left(\Delta G^{0}\right)$, standard enthalpy changes $\left(\Delta H^{0}\right)$, and standard entropy changes $\left(\Delta S^{0}\right)$ by performing the adsorption experiments at different temperatures $\left(15,25,35\right.$, and $\left.45^{\circ} \mathrm{C}\right)$ to attain knowledge about the energy changes, and according to the following equation (Guo et al. 2014):

$$
\ln k_{d}=\frac{\Delta S^{\circ}}{R}-\frac{\Delta H^{\circ}}{R T}
$$

where the $\mathrm{k}_{\mathrm{d}}$ is equilibrium constant and its value was calculated by the ratio of $\mathrm{q}_{\mathrm{e}}$ and $\mathrm{C}_{\mathrm{e}} . \Delta \mathrm{H}^{0}$ and $\Delta \mathrm{S}^{0}$ values were obtained from the slope and the intercept of the linear plots of In ( ) versus $1 / T$, respectively. $R$ is the universal gas constant $(8.314 \mathrm{~J} / \mathrm{mol} . \mathrm{K})$ and $\mathrm{T}$ is the temperature $(\mathrm{K})$. Where $\mathrm{Kd}$ is the adsorption equilibrium constant and can be presented from initial and equilibrium concentration $\left(\mathrm{C}_{\mathrm{o}}\right.$ and $\left.\mathrm{C}_{\mathrm{e}}\right)$ of SDBS:

$$
K_{d}=\frac{c_{0}-c_{e}}{c_{s}} \times \frac{V}{W}
$$

where $V$ and $W$ are the solution volume $(\mathrm{mL})$ and the adsorbent mass $(\mathrm{g})$, respectively. The $\Delta \mathrm{G}^{\circ}$ is the change in Gibbs free energy $(\mathrm{J} / \mathrm{mol})$ and was estimated at different temperatures, which can be expressed as follows equation:

$$
\Delta G^{0}=\Delta H^{0}-T \Delta S^{0}
$$

\section{Results And Discussion}

\subsection{Nano-adsorbent characterization}

FTIR spectra was employed in order to know the significance of functional groups placed on the surface of materials. The FTIR spectra of orange peel (a), G (b), MG (c), NG (d) and MNG (e) were shown in Fig. 1. According this figure, in the FTIR spectrum of orange peel and all synthesized samples, the absorption band at $3420 \mathrm{~cm}^{-1}$ is assigned to $\mathrm{O}-\mathrm{H}$ stretching vibration. The presence of two peaks at $2858 \mathrm{~cm}^{-1}$ and $2925 \mathrm{~cm}^{-1} \mathrm{are}^{-}$ associated to symmetric and the asymmetric stretching vibration of $\mathrm{C}-\mathrm{H},-\mathrm{CH}_{2}-\mathrm{NH}-\mathrm{CH}_{2}-$ or $-\mathrm{CH}_{2}-\mathrm{NH}_{-} \mathrm{CH}_{3}$, respectively (Hao et al. 2010). Also, the $1736 \mathrm{~cm}^{-1}$ and $1075 \mathrm{~cm}^{-1}$ peaks that were achieved in the FTIR spectra ascribed to $C=0$ bond of epoxy groups (Xue et al. 2015). The band located at $1248 \mathrm{~cm}^{-1}$ and $1384 \mathrm{~cm}^{-1}$ corresponding respectively to stretching vibration of $\mathrm{C}-\mathrm{N}$ and $\mathrm{N}-\mathrm{CH}_{3}$, which represents an increase of nitrogen in the structure of graphene. When the nitrogen atom attaches to the carbon lattice structure, would be expected adsorption peaks in the range of $1200 \mathrm{~cm}^{-1}$ to $1600 \mathrm{~cm}^{-1}$ (Misra et al. 2007). The peaks observed at $1248 \mathrm{~cm}^{-1}$ and $1384 \mathrm{~cm}^{-1}$ in $\mathrm{N}$-doped graphene curves (curves $\mathrm{d}$ and e) illustrating the replacement of nitrogen atom with carbon atom in a continuous carbon lattice. Therefore, the $\mathrm{N}$-doping process in graphene sheets associated with the $\mathrm{C}-\mathrm{N}$ bond. Furthermore, two major adsorption peaks around $872 \mathrm{~cm}^{-1}$ and $588 \mathrm{~cm}^{-1}$ in N-doped graphene curves (curves $\mathrm{d}$ and e) corresponding respectively to the $\mathrm{N}-\mathrm{H}$ bending vibration and $\mathrm{Fe}-\mathrm{O}$ stretching vibration, confirming that the decoration of $\mathrm{Fe}_{3} \mathrm{O}_{4}$ magnetic nanoparticles on graphene nanosheets (Hao et al. 2010, Saleh et al. 2017). 
In order to determine the porous structure and synthesized adsorbents surface area, the BET analysis was performed. The results achieved of $\mathrm{N}_{2}$ adsorption-desorption isotherms containing the BET surface area, the average pore diameters and total pore volumes of synthesized adsorbents (G, MG, GN and MGN) are summarized in Table 1. The BET results demonstrated that the specific surface area of G, MG, GN and MGN were computed as 2525.1, 1534.1, 1640.3 and $1362.5 \mathrm{~m}^{2} / \mathrm{g}$, respectively. It was as anticipated, the BET surface area of MNG adsorbent was diminished both related to the surface $\mathrm{N}$-doping and magnetite $\left(\mathrm{Fe}_{3} \mathrm{O}_{4}\right)$ nanoparticles in graphene structure. Based on the IUPAC adsorption-desorption isotherms, of all synthesize material seem a hybrid of Type I and IV isotherm, which proves the mesoporosity development.The Raman spectroscopy define as a non-destructive and powerful chemical analysis technique which can provide information about number of layers, order, vibrational modes of molecules and features of graphene-based materials. The Raman peaks are provided in Fig. 2. It is well-known that the Raman spectra of MNG commonly show two main peaks around 1561 and $1339 \mathrm{~cm}^{-1}$, which are assigned to $D$ and $G$ peak, respectively. The $D$ band is ascribed to $\mathrm{sp}^{3}$ carbon atoms vibration with structural defects, while the G-band is due to $\mathrm{sp}^{2}$ bonded carbon atoms vibration in a graphitic domain. The 2D-band was acquired at $2633 \mathrm{~cm}^{-1}$, which specified that the place of the 2D-bond to be more sensitive to the graphene layers number. Furthermore, the MNG layers number can be ascertained from the peak intensity ratio, $\mathrm{I}_{2 \mathrm{D}} / \mathrm{I}_{\mathrm{G}}$. In this way, the $\mathrm{I}_{2 \mathrm{D}} / \mathrm{I}_{\mathrm{G}}$ intensity ratio of single, double, triple and multi-(> 4) layers graphene is higher than 1.6, 0.8, 0.3 and 0.07, respectively (Ray et al. 2012, Akhavan et al. 2014). In the current study, the $\mathrm{I}_{2 \mathrm{D}} / \mathrm{I}_{\mathrm{G}}$ ratio was found to be 0.6 , suggesting that the double, triple layer structure of graphene sheets synthesized. AFM imaging provides a wealth of information from geometry and topology of prepared MNG sheets. The AFM magnified image of MNG with line scan are presented in Fig. 3 . The height measurement AFM scan revealed that the width of MNG nano sheets was between 0.8 to $1 \mathrm{~nm}$, confirming that the single layer and high quality of synthesized MNG nano sheets. The magnetic properties of MG and MNG and were carried out with a vibrating sample magnetometer (VSM) and results are depicted in Fig. 4. The magnetization values of $M G$ and MNG were found to be 14 and $10 \mathrm{emu} / \mathrm{g}$, respectively. Accordingly, the reduction in the magnetization value of MNG sample can be illuminated by the introduction of nitrogen functional groups on MNG surface and the proportionate reduction in $\mathrm{Fe}_{3} \mathrm{O}_{4}$ nanoparticles per unit weight. Meanwhile, the magnetism curves also represented negligible coercivity and hysteresis, observing that the MG and MNG could be rapidly allowed to separate from the liquid phase after adsorption experiment by magnet, which approves that the strong magnetic characteristics of the prepared nano adsorbents for SDBS removal. The surface morphologies of G and magnetic MNG were imaged by SEM as shown in Fig. 5. It was clearly seen from Fig.5a that the obtained graphene nanosheets consisted of thin, folded, and some crumpled structures with wrinkled edge. The SEM image of MNG (Fig. 5 (b)) revealed that $\mathrm{Fe}_{3} \mathrm{O}_{4}$ NPs were successfully anchored on the surface of graphene sheets and the average sizes of the $\mathrm{Fe}_{3} \mathrm{O}_{4} \mathrm{NPs}$ decorated on the graphene surface were estimated about $100 \mathrm{~nm}$ with a uniform distribution. The CHNS elemental analysis of graphene and MNG were presented in Table 2. The results shows that carbon contents (86.10\%) in MNG slightly decreased while the content of nitrogen increased to $1.9 \%$ due to the $N$-doped graphene nanosheets.

\subsection{Adsorption experiment}

\subsubsection{Effect of contact time}


It is obvious that the contact time is one of the most essential parameters in the adsorption process because of determine the needed time for SDBS molecules adsorption on the MNG nano composite to attain equilibrium. Hence, the influence of contact time on the removal efficiency of SDBS onto the as-synthesized nano adsorbent was studied in the time range of 5-90 min in various SDBS concentrations and the obtained results are presented in Fig. 6. The results of adsorption experiments suggested that the adsorption rate of SDBS on MNG occurs sharply at the first contact time of $30 \mathrm{~min}$ and then approaches a constant value. From the results, the time to attain equilibrium was 30 min with $87 \%$ removal of SDBS observed. Also, the equilibrium adsorption capacity $\left(\mathrm{q}_{\mathrm{e}}\right)$ of $M N G$ increased with increasing time $\left(\mathrm{q}_{\mathrm{e}}=217 \mathrm{mg} / \mathrm{g}\right)$ was mainly due to the interaction between SDBS molecule and surface functional groups of nitrogen. It can be expressed that the rapid equilibrium state may be due to the presence of availability of a large number of vacant sites on the nano adsorbent surface, while the diminish can be coupled with a low SDBS mass transfer from the liquid phase to the MNG nano composite surface. These results are agree with some reported studies in the literature for the adsorption process of SDBS (Valizadeh et al. 2016, Kahya et al. 2018).

\subsubsection{Effect of solution $\mathrm{pH}$}

It is well known that the solution $\mathrm{pH}$ can play a main controlling parameter for adsorption of pollutants from liquid solution because it influences the adsorption studies greatly by affecting both the kind of ion $\left(\mathrm{H}^{+}\right.$or $\left.\mathrm{OH}^{-}\right)$ solution and the adsorbates ionization degree in solution (Bian et al. 2015, Cui et al. 2015). For this purpose, the influence of different pH (2.0 to 10.0) on the adsorption of SDBS onto MNG nanoparticles was evaluated (Fig. 9). According to Fig. 7, the removal efficiency and adsorption capacity of SDBS by synthesized nanoadsorbent were increased with decreasing the $\mathrm{pH}$ value. Hereupon, the highest adsorption capacity was happened in $\mathrm{pH} 2$ and 3. The adsorption studies at $\mathrm{pH}=3$ was conducted because of the economic and environmental reasons, and this $\mathrm{pH}$ value was considered as the optimum $\mathrm{pH}$ for SDBS adsorption. Thus, subsequent adsorption experiments were carried out at $\mathrm{pH}=3$. It is observed that the removal efficiency of the SDBS reached a maximum at $\mathrm{pH}=3$ with $94 \%$ removal $\left(\mathrm{q}_{\mathrm{e}}=314 \mathrm{mg} / \mathrm{g}\right)$. This trend can be illustrated by the fact that at this $\mathrm{pH}$ value the protonation reaction by neutralization of the negative charges and enhancement of the number of positive charges on the active sites of the adsorbent surface increases and electrostatic interactions between the MNG surface and SDBS play a significant function. Additionally, another reason might be due to the nitrogen groups in the structure of MNG increases positive charges of adsorbent surface and finally improves the removal of SDBS from aqueous solution. On the other hand, at alkaline pH values, the removal rate of SDBS by MNG was decreased because of the stronger electrostatic repulsion. Inyinbor et al. investigated the Rhodamine B dye removal efficiency applying Raphiahookerie fruit epicarp as adsorbent in a pH range of 2.0 to 9.0, and higher dye removal efficiency was obtained at $\mathrm{pH}=3.0$ and the adsorption capacity increased with decreasing the solution $\mathrm{pH}$ (Inyinbor et al. 2016). The removal of SDBS from an aqueous solution can be further explained by $\mathrm{pH}_{z p c}$. With applying the $\mathrm{pH}_{z p c}$ can be determined the charge on a solid surface is zero, and this point the sum total of surface positive and negative charges on adsorbent surface are balanced (Stafiej and Pyrzynska 2007, Sarswat and Mohan 2016). In this research, the $\mathrm{pH}_{\mathrm{zpc}}$ of adsorbent was measured by introducing $10 \mathrm{mg}$ of adsorbent into $1 \mathrm{mM} \mathrm{NaCl}$ aqueous solution. Fig. 8 reveals the change surface charges of MNG nano adsorbent with $\mathrm{pH}_{\mathrm{zpc}}$ curve. The $\mathrm{pHzpc}$ was found to be 7.4 according to the Figure 1. This $\mathrm{pH}$ shows that the surface of adsorbent possess a positive charge in the pHzpc lower than 7.4 and possess a negative charge in pHzpc greater than 7.4. 


\subsubsection{Effect of adsorbent dosage}

The effect of adsorbent dosage on the removal efficiency of SDBS by MNG was examined and the results illustrated in Fig. 9. According the results, the equilibrium adsorption capacity being strongly dependent on the raise of the adsorbent dosage. Under a given operating conditions, the maximum removal efficiency of SDBD was achieved at $0.15 \mathrm{~g} / \mathrm{L}$ of adsorbent dosage. It is found that with increasing absorbent dosage from 0.1 to $0.25 \mathrm{~g} / \mathrm{L}$, the SDBS removal percentage increased from $86 \%$ to $100 \%$ and the equilibrium adsorption capacity $\left(q_{e}\right)$ decreased from 360 to $199 \mathrm{mg} / \mathrm{g}$. That is due to the enhance of the number of available active sites on the surface of the MNG at a higher amount of adsorbent, which lead to more SDBS trapping onto the adsorbent surface. The results shows that although the removal rate increases with increase in adsorbent dosage, but the amount of SDBS adsorbed onto per gram nano adsorbent decreases. The reason can related to the lack of the saturation of available active sites for the absorption of pollutant. This research approved the results achieved by other authors (Zhang et al. 2011, Sumalatha et al. 2014, Wong et al. 2020).

\subsubsection{Effect of initial concentration}

In this section, the influence of initial pollutant concentration on adsorption capacity was investigated under respective optimal $\mathrm{pH}$. As revealed in Fig. 10, with raising concentrations of SDBS from 50 to $150 \mathrm{mg} / \mathrm{L}$, the adsorption capacity was raised significantly from 305 to $538 \mathrm{mg} / \mathrm{g}$. This can be clarified owing to the raise of the driving force by raise of SDBS concentration in the aqueous phase and thereby to raise in contact between SDBS molecules with available adsorption sites on the MNG surface. However, the removal percentage of SDBS by MNG was found to reduce from $98 \%$ to $54 \%$ with increase in initial pollutant concentration. Since at lower concentrations, the ratio of the initial number of molecules adsorbed to the available surface area of nano adsorbent is huge, whereas at higher concentrations the available sites of adsorption become fewer, and therefore the removal rate of SDBS which depends on the initial concentration, reduces.

\subsubsection{Adsorption kinetics}

The mechanism of SDBS adsorption process, with the help two linear equations including the pseudo-first-order and pseudo-second-order kinetic models were applied to describe the empirical data of SDBS adsorption onto MNG adsorbent and the models results are provided in Table 3. A comparison between the regression correlation coefficients $\left(R^{2}=0.9999\right)$ values determines the SDBS molecules adsorption on prepared nano adsorbent followed pseudo-second-order kinetic model to achieved data compared to the pseudo-first-order adsorption model. It is observed that the calculated adsorption capacity $\left(\mathrm{q}_{\mathrm{e} 2}\right)$ from the pseudo-second-order kinetic model, are favorable consistent with empirical values $\left(\mathrm{q}_{\mathrm{e}}\right.$ exp $)$ than the other one. These facts proves that the empirical data are very well exhibited by pseudo-second-order kinetic model. Our data are given in Table 3 clearly showed a similar trend of reduce in the pseudo-second-order constant $\left(k_{2}\right)$ with enhance in initial SDBS concentrations, showing the fast saturation of the available active sites of MNG by SDBS and as a result in reaching equilibrium at lower initial concentrations in adsorption system. Literature study also suggested that the chemical adsorption processes controls reaction rate in batch system, which related to the sharing or electron exchange between SDBS and adsorbent sites. Consequently, the covalent chemical bonds facilitates attachment of SDBS molecules on the adsorbent surface in solution. Bhandari and Gogate also reported similar results when they investigated activated coconut shell as adsorbent for SDBS removal from aqueous solution. They showed that the adsorption of SDBS onto activated coconut shell as adsorbent followed the pseudo- 
second-order mechanism and adsorption of SDBS was a chemisorption process (Bhandari and Gogate 2018). Robati was concluded that the pseudo-second order model satisfactorily explain the adsorption kinetics of lead onto MWCNTs and MWCNT-COOH surfaces (Robati 2013).

Based on the intra-particle diffusion diagram which shown in Fig. 11, the SDBS adsorption onto MNG comprise two stages exhibited a multilinearity. The first stage was mainly ascribed to the boundary layer diffusion or macro-pore diffusion, and second stage was owing to the intra particle diffusion or micro-sore diffusion.

\subsubsection{Adsorption isotherms}

The adsorption isotherm models are utilized to explain the quantity of adsorbate on the surface as a function of concentration at constant temperature. Hence, to perceive the SDBS adsorption mechanism onto MNG adsorbent, the linear Langmuir, Freundlich, and Redlich-Peterson ( $R-P)$ isotherm models were employed to describe the equilibrium empirical result fitting curves are displayed in Fig. 12 ( $a, b$ and c). These equilibrium isotherm equations models also are explained by the appropriate constant values, and which demonstrated the surface features and described the adsorption capacity of the nano adsorbent. Moreover, Table 4 implies the model constant values and the regression coefficients $\left(R^{2}\right)$ are achieved by fitting empirical data into the stated isotherms. Among three models, the Langmuir isotherm was considered well fit to the SDBS adsorption than the other studied isotherm models due to the high correlation coefficient value $\left(R^{2}=0.9983\right)$. According to the literature, it could be clearly concluded that the SDBS adsorption onto MNG nano adsorbent was monolayer coverage (uniform) and the homogeneous in nature without any interaction between the adsorbed SDBS and with the equivalent energy of the whole sites on the nano adsorbent surface sites. The Redlich-Peterson (R-P) isotherm model also blends the postulation of both the Langmuir and Freundlich models; and so representing that the adsorption mechanism is conformity with the single and multi-layer adsorption. Based on the RedlichPeterson ( $R-P)$ isotherm model, the adsorption can be classified as Freundlich $(\beta>1)$ and Langmuir equation ( $\beta$ $=1$ ). From the results, the $\beta$ value was estimated to be 1 , thus illustrating that the SDBS adsorption process has a higher correlation toward the Langmuir model. Therefore, the maximum adsorption capacities values $\left(\mathrm{q}_{\mathrm{m}}\right)$ of SDBS obtained for the Langmuir isotherm model was calculated to be $555.55 \mathrm{mg} / \mathrm{g}$. Silvio et al., studied the adsorption of SDBS from liquid solution by modified natural zeolite with cetyl trimethylammonium bromide (CTAB) and found that isotherm data fitted very well with the Langmuir isotherm model (Taffarel and Rubio 2010). Further, Vale et al. found the adsorption of SDS and SDBS using polyvinyl chloride (PVC) had the greatest agreement with the Langmuir kinetic model (Vale and McKenna 2005).

\subsubsection{Adsorption thermodynamic}

To realize the effect of temperature on SDBS removal efficiency, the thermodynamic parameters were assessed at studied temperatures are given in Table 5. The plots of $\ln \mathrm{K}_{d}$ versus $1 / T$ for SDBS adsorption onto MNG can be shown from Fig. 13. As observed in Table $5, \Delta H^{0}$ have a mean value of $+59.08 \mathrm{~J} / \mathrm{mol}$. According to the positive values of $\Delta \mathrm{H}^{0}\left(\Delta \mathrm{H}^{0}>0\right)$ and the negative slope of Van't Hoff confirming the adsorption process on the MNG nano adsorbent is an endothermic reaction which is explained by the increase of SDBS adsorption onto MNG with rising temperature. Similar observation have been achieved in Zhang et al studies for SDBS adsorption by modified activated carbon with ferreous sulfate (Zhang et al. 2009). Additionally, the $\Delta H^{0}$ value is studied to realize whether the SDBS adsorption on prepared nano adsorbents is physical or chemical. For the 
physical adsorption the $\Delta \mathrm{H}^{0}$ value is between $20-80 \mathrm{~kJ} / \mathrm{mol}$ while chemical adsorption occurs in the range of 80 to $400 \mathrm{~kJ} / \mathrm{mol}$ (Rodrigues et al. 2011). Based on the estimated $\Delta \mathrm{H}^{0}$ value can be elucidated that the interaction between SDBS and MNG nano adsorbent reflects the physical mechanism. Moreover, the negative value of $\Delta G^{0}\left(\Delta G^{0}<0\right)$ exhibits that the adsorption of SDBS onto magnetic nano-adsorbent is spontaneous in nature at various temperatures. In this study, the $\Delta G^{0}$ value varied from -67.40 to $-74.43 \mathrm{~kJ} / \mathrm{mol}$ with temperature increasing from 288 to $318 \mathrm{~K}$. The increase in negative values of $\Delta G^{0}$ with an enhancing temperature proving that more efficient and favorable adsorption of SDBS at higher temperatures due to reduce viscosity and solubility of SDBS in the solution and activation energy. Eventually, $\Delta S^{0}$ positive values $(+234.12$ $(\mathrm{J} / \mathrm{mol}))$ is caused by the increase in degree of freedom by the adsorbed species in solution and shows raised randomness at solid-liquid interface during the SDBS adsorption onto MNG. Also, positive values of $\Delta S^{0}$ associated with the structural changes in adsorbate and nano adsorbent.

\subsubsection{Desorption and regeneration study}

From a practical perspective, stability and regeneration are one of the most important features of an ideal nano adsorbent since can help reduce economic costs and environmental impacts and also saving more time remarkably. In this study, to determine the possibility of recyclable and reusability of MNG as an adsorbent, we implemented desorption experiments under batch experimental conditions. Therefore, in this study, desorption of SDBS was carried out in $20 \mathrm{ml}$ of methanol and ethanol. It is found that the desorption efficiency using methanol and ethanol were obtained $88.30 \%$ and $60.16 \%$, respectively, which indicated the SDBS can be effectively regenerated using methanol compared to ethanol solvent (Fig. 14). The reusability of MNG was examined by doing the adsorption-desorption process for five successive cycles and the adsorption performance in each cycle was calculated, which was illustrated in Fig. 15. It can be depicted from Fig. 14, the change of SDBS adsorption performances was negligible during five adsorption- desorption cycles and desorption percentage was obtained at $87 \%$ after the last cycle. According to the background information, the lower removal efficiency of MNG in adsorption-desorption cycles may be due to the fact that in the first regeneration step, huge number of active sites on the MNG adsorbent surface have not yet been occupied by pollutant, but in the next steps, remains a few adsorption sites and thereby the efficiency of MNG decrease. Besides, the magnetic power of MNG nano adsorbent did not reduce compared to the initial step, and thus the nano adsorbent could be effortlessly separated and reused by a magnet before and after the adsorptiondesorption process. Overall, our regeneration studies proposed that this nano material can be repeatedly employed as efficient adsorbent for practical application of wastewater treatment process.

\section{Conclusion}

In the current study, we reported a chemical procedure in order to fabricate a highly effective nano adsorbent from orange peel for purification of SDBS from aqueous environment. The prepared MNG was characterized very well using various analysis, proving that the iron oxide was uniformly decorated on the surface of nitrogendoped graphene sheet. The batch adsorption system experiments exhibited that the maximum SDBS removal of $98 \%$ was occurred at adsorbent dosage of $0.1 \mathrm{~g} / \mathrm{L}$, contact time of $30 \mathrm{~min}$, temperature of $45^{\circ} \mathrm{C}$ and values $\mathrm{pH}$ of 3 and initial concentration of $50 \mathrm{mg} / \mathrm{L}$. The adsorption of SDBS onto MNG adsorbent was found to be highly dependent on values of $\mathrm{pH}$. The experimental data also highlighted that the adsorption kinetic favorably demonstrated by the pseudo-second-order kinetic model and the negative value of $\Delta G^{0}\left(\Delta G^{0}<0\right)$ and positive 
values of $\Delta \mathrm{H}^{0}\left(\Delta \mathrm{H}^{0}>0\right)$ confirmed that endothermic phenomena and spontaneous nature of SDBS adsorption onto magnetic nano-adsorbent. The maximum adsorption capacity calculated by the Langmuir model was 556 $\mathrm{mg} / \mathrm{g}$, supporting monolayer coverage of SDBS molecules at the surface of nano adsorbent. Reusability studies showed the SDBS can be recovered rapidly and efficiently from the produced MNG surface applying methanol solution with a high yield of $87 \%$ after five cycles. It is believed that this research would be valuable in the water and wastewater treatment applications due to the simplicity, reproducibility, high performance, low cost, as well selectivity of this approach.

\section{Declarations}

\section{Data Availability}

The datasets generated during and analysed during the current study are available from the corresponding author on reasonable request.

\section{Ethics Approval}

The authors confirm that this article is original research and has not been published or presented previously in any journal or conference in any language (in whole or in part).

\section{Competing Conflict of Interest}

The authors declare that they have no conflict of interest.

\section{Funding}

This work was financially supported by the Tarbiat Modares University (TMU), Iran.

\section{Contributions}

The participation of Arash Khoshnoodfar includes the Visualization, Investigation, Writing - original draft preparation. Project administration, Supervision, Conceptualization, Methodology, Funding acquisition was done by Nader Bahramifar and the participation of Habibollah Younesi includes help to Data curation, Resources, Formal analysis and investigation, Writing - review \& editing.

\section{Acknowledgments}

The authors wish to thank Tarbiat Modares University's foundation for their financial support and Mrs. Haghdoust (Technical Assistant of Environmental Laboratory) for her assistance.

\section{References}

Ai L, Zhang C, Chen Z (2011) Removal of methylene blue from aqueous solution by a solvothermal-synthesized graphene/magnetite composite. Journal of hazardous materials 192 (3), 1515-1524.

Akhavan O, Bijanzad K, Mirsepah A (2014) Synthesis of graphene from natural and industrial carbonaceous wastes. RSC Advances 4 (39), 20441-20448. 
Bhandari PS, Gogate PR (2018) Kinetic and thermodynamic study of adsorptive removal of sodium dodecyl benzene sulfonate using adsorbent based on thermo-chemical activation of coconut shell. Journal of Molecular Liquids 252, 495-505.

Bian Y, Bian Z-Y, Zhang J-X, Ding A-Z, Liu S-L, Wang H (2015) Effect of the oxygen-containing functional group of graphene oxide on the aqueous cadmium ions removal. Applied Surface Science 329, 269-275.

Cui L, Guo X, Wei Q, Wang Y, Gao L, Yan L, Yan T, Du B (2015) Removal of mercury and methylene blue from aqueous solution by xanthate functionalized magnetic graphene oxide: sorption kinetic and uptake mechanism. Journal of colloid and interface science 439, 112-120.

Freundlich H (1907) Über die adsorption in lösungen. Zeitschrift für physikalische Chemie 57 (1), 385-470.

Garcia-Delgado R, Cotoruelo L, Rodriguez J (1992) Adsorption of anionic surfactant mixtures by polymeric resins. Separation science and technology 27 (8-9), 1065-1076.

Guo X, Du B, Wei Q, Yang J, Hu L, Yan L, Xu W (2014) Synthesis of amino functionalized magnetic graphenes composite material and its application to remove $\mathrm{Cr}(\mathrm{VI}), \mathrm{Pb}$ (II), $\mathrm{Hg}$ (II), Cd (II) and Ni (II) from contaminated water. Journal of hazardous materials 278, 211-220.

Hao Y-M, Man C, Hu Z-B (2010) Effective removal of Cu (II) ions from aqueous solution by amino-functionalized magnetic nanoparticles. Journal of hazardous materials 184 (1-3), 392-399.

Ho Y-S (2006) Review of second-order models for adsorption systems. Journal of hazardous materials 136 (3), 681-689.

Inyinbor A, Adekola F, Olatunji GA (2016) Kinetics, isotherms and thermodynamic modeling of liquid phase adsorption of Rhodamine B dye onto Raphia hookerie fruit epicarp. Water Resources and Industry 15, 14-27.

Jiang D, Liu Q, Wang K, Qian J, Dong X, Yang Z, Du X, Qiu B (2014) Enhanced non-enzymatic glucose sensing based on copper nanoparticles decorated nitrogen-doped graphene. Biosensors and Bioelectronics 54, $273-278$.

Kahya N, Kaygusuz H, Erim FB (2018) Aqueous removal of sodium dodecyl benzene sulfonate (SDBS) by crosslinked chitosan films. Journal of Polymers and the Environment 26 (5), 2166-2172.

Langmuir I (1918) The adsorption of gases on plane surfaces of glass, mica and platinum. Journal of the American Chemical society 40 (9), 1361-1403.

Leyva-Ramos R, Ocampo-Pérez R, Bautista-Toledo I, Rivera-Utrilla J, Medellín-Castillo N, Aguilar-Madera C (2020) The adsorption kinetics of sodium dodecylbenzenesulfonate on activated carbon. Branched-pore diffusional model revisited and comparison with other diffusional models. Chemical Engineering Communications 207 (5), 705-721.

Li H, Yang Y, Gao J, Li X, Zhou Z, Wang N, Du P, Zhang T, Feng J (2020) Degradation of sodium dodecyl benzenesulfonate by vacuum ultraviolet irradiation. Journal of Water Process Engineering 34, 101172. 
Li S-S, Lin C-W, Wei K-C, Huang C-Y, Hsu P-H, Liu H-L, Lu Y-J, Lin S-C, Yang H-W, Ma C-CM (2016) Non-invasive screening for early Alzheimer's disease diagnosis by a sensitively immunomagnetic biosensor. Scientific reports $6(1), 1-11$.

Méndez-Díaz J, Sánchez-Polo M, Rivera-Utrilla J, Bautista-Toledo M (2009) Effectiveness of different oxidizing agents for removing sodium dodecylbenzenesulphonate in aqueous systems. water research 43 (6), 1621-1629.

Misra A, Tyagi PK, Rai P, Misra D (2007) FTIR Spectroscopy of multiwalled carbon nanotubes: a Simple approachto study the nitrogen doping. Journal of nanoscience and nanotechnology 7 (6), 1820-1823.

Muramatsu H, Kim YA, Yang KS, Cruz-Silva R, Toda I, Yamada T, Terrones M, Endo M, Hayashi T, Saitoh H (2014) Rice Husk-Derived Graphene with Nano-Sized Domains and Clean Edges. Small 10 (14), 2766-2770.

Nazari M, Ayati B (2019) Removing Sodium Dodecyl Benzene Sulfonate Using a Hybrid Electrocoagulation/Flotation and Photocatalytic System. Journal of Water and Environmental Nanotechnology 4 (3), 236-243.

Parhizgar F, Alishahi A, Varasteh H, Rezaee H (2017) Removing sodium dodecyl benzene sulfonate (SDBS) from aqueous solutions using chitosan. Journal of Polymers and the Environment 25 (3), 836-843.

Piccin J, Dotto G, Pinto L (2011) Adsorption isotherms and thermochemical data of FD\&C Red $\mathrm{n} 40$ binding by chitosan. Braz J Chem Eng, 295-304.

Ray AK, Sahu RK, Rajinikanth V, Bapari H, Ghosh M, Paul P (2012) Preparation and characterization of graphene and Ni-decorated graphene using flower petals as the precursor material. Carbon 50 (11), 4123-4129.

Robati D (2013) Pseudo-second-order kinetic equations for modeling adsorption systems for removal of lead ions using multi-walled carbon nanotube. Journal of nanostructure in Chemistry 3 (1), 55.

Rodrigues LA, da Silva MLCP, Alvarez-Mendes MO, dos Reis Coutinho A, Thim GP (2011) Phenol removal from aqueous solution by activated carbon produced from avocado kernel seeds. Chemical engineering journal 174 (1), 49-57.

Saleh TA, Tuzen M, Sarı A (2017) Polyethylenimine modified activated carbon as novel magnetic adsorbent for the removal of uranium from aqueous solution. Chemical Engineering Research and Design 117, 218-227.

Sarswat A, Mohan D (2016) Sustainable development of coconut shell activated carbon (CSAC) \& a magnetic coconut shell activated carbon (MCSAC) for phenol (2-nitrophenol) removal. RSC advances 6 (88), 8539085410 .

Singh R, Kumar M, Khajuria H, Ladol J, Sheikh HN (2018) Hydrothermal synthesis of magnetic Fe 30 4nitrogen-doped graphene hybrid composite and its application as photocatalyst in degradation of methyl orange and methylene blue dyes in presence of copper (II) ions. Chemical Papers 72 (5), 1181-1192.

Stafiej A, Pyrzynska K (2007) Adsorption of heavy metal ions with carbon nanotubes. Separation and purification technology 58 (1), 49-52. 
Sumalatha B, Kumar Y, Kumar K, Babu D, Narayana A, Das K, Venkateswarulu T (2014) Removal of indigo carmine from aqueous solution by using activated carbon. Research Journal of Pharmaceutical, Biological and Chemical Sciences 5 (2), 912-922.

Taffarel SR, Rubio J (2010) Adsorption of sodium dodecyl benzene sulfonate from aqueous solution using a modified natural zeolite with CTAB. Minerals Engineering 23 (10), 771-779.

Tan X, Fang M, Chen C, Yu S, Wang X (2008) Counterion effects of nickel and sodium dodecylbenzene sulfonate adsorption to multiwalled carbon nanotubes in aqueous solution. Carbon 46 (13), 1741-1750.

Vale HM, McKenna TF (2005) Adsorption of sodium dodecyl sulfate and sodium dodecyl benzenesulfonate on poly (vinyl chloride) latexes. Colloids and Surfaces A: Physicochemical and Engineering Aspects 268 (1-3), 6872.

Valizadeh S, Younesi H, Bahramifar N (2016) Highly mesoporous K2CO3 and KOH/activated carbon for SDBS removal from water samples: batch and fixed-bed column adsorption process. Environmental Nanotechnology, Monitoring \& Management 6, 1-13.

Wang H, Maiyalagan T, Wang X (2012a) Review on recent progress in nitrogen-doped graphene: synthesis, characterization, and its potential applications. Acs Catalysis 2 (5), 781-794.

Wang S, Zhang L, Xia Z, Roy A, Chang DW, Baek JB, Dai L (2012b) BCN graphene as efficient metal-free electrocatalyst for the oxygen reduction reaction. Angewandte Chemie International Edition 51 (17), $4209-4212$.

Wang Y, Shao Y, Matson DW, Li J, Lin Y (2010) Nitrogen-doped graphene and its application in electrochemical biosensing. ACS nano 4 (4), 1790-1798.

Wang Z-L, Yan J-M, Zhang Y-F, Ping Y, Wang H-L, Jiang Q (2014) Facile synthesis of nitrogen-doped graphene supported AuPd-CeO 2 nanocomposites with high-performance for hydrogen generation from formic acid at room temperature. Nanoscale 6 (6), 3073-3077.

Wong S, Abd Ghafar N, Ngadi N, Razmi FA, Inuwa IM, Mat R, Amin NAS (2020) Effective removal of anionic textile dyes using adsorbent synthesized from coffee waste. Scientific reports 10 (1), 1-13.

Wu S, Zhang K, Wang X, Jia Y, Sun B, Luo T, Meng F, Jin Z, Lin D, Shen W (2015) Enhanced adsorption of cadmium ions by 3D sulfonated reduced graphene oxide. Chemical engineering journal 262, 1292-1302.

Xue B, Zhu J, Liu N, Li Y (2015) Facile functionalization of graphene oxide with ethylenediamine as a solid base catalyst for Knoevenagel condensation reaction. Catalysis Communications 64, 105-109.

Yang G, Li L, Rana RK, Zhu J-J (2013) Assembled gold nanoparticles on nitrogen-doped graphene for ultrasensitive electrochemical detection of matrix metalloproteinase-2. Carbon 61, 357-366.

Yang HW, Lin CW, Hua MY, Liao SS, Chen YT, Chen HC, Weng WH, Chuang CK, Pang ST, Ma CCM (2014) Combined Detection of Cancer Cells and a Tumor Biomarker using an Immunomagnetic Sensor for the Improvement of Prostate-Cancer Diagnosis. Advanced Materials 26 (22), 3662-3666. 
Yang X, Zhang X, Ma Y, Huang Y, Wang Y, Chen Y (2009) Superparamagnetic graphene oxide-Fe 304 nanoparticles hybrid for controlled targeted drug carriers. Journal of materials chemistry 19 (18), $2710-2714$.

Yuh-Shan H (2004) Citation review of Lagergren kinetic rate equation on adsorption reactions. Scientometrics $59(1), 171-177$.

Zhang L, Song X, Liu X, Yang L, Pan F, Lv J (2011) Studies on the removal of tetracycline by multi-walled carbon nanotubes. Chemical engineering journal 178, 26-33.

Zhang Z, Deng Y, Shen M, Han W, Chen Z, Xu D, Ji X (2009) Investigation on rapid degradation of sodium dodecyl benzene sulfonate (SDBS) under microwave irradiation in the presence of modified activated carbon powder with ferreous sulfate. Desalination 249 (3), 1022-1029.

\section{Tables}

Table 1. BET surface area $\left(\mathrm{S}_{\mathrm{BET}}\right)$, total pore volume and average pore diameters of prepared adsorbents.

\begin{tabular}{rrrr}
\hline Adsorbent & $\left(\mathrm{S}_{\mathrm{BET}}\left(\mathrm{m}^{2} / \mathrm{g}\right.\right.$ & $\left(\mathrm{V}_{\text {total }}\left(\mathrm{cm}^{3} / \mathrm{g}\right.\right.$ & $\left(\mathrm{D}_{\text {Ave }} \cdot \mathrm{BJH}(\mathrm{nm}\right.$ \\
\hline $\mathrm{G}$ & 2525.1 & 1.4684 & 0.9 \\
$\mathrm{MG}$ & 1534.1 & 0.8014 & 0.8 \\
$\mathrm{GN}$ & 1640.3 & 0.9466 & 0.9 \\
$\mathrm{MGN}$ & 1362.5 & 0.8081 & 0.9 \\
\hline
\end{tabular}

Table 2. Elemental analysis of each step of G and MNG nanosheets.

\begin{tabular}{lllll}
\hline Adsorbent & Weight (\%) & & \\
\hline \multirow{4}{*}{ GNG } & Carbon & Hydrogen & Nitrogen & Sulfur \\
MNG & 95.58 & 0.71 & 0.66 & 0.08 \\
& 86.10 & 0.69 & 1.9 & 0.27 \\
\hline
\end{tabular}

Table 3. Kinetic adsorption parameters obtained using pseudo-first-order and pseudo-second-order models.

\begin{tabular}{|c|c|c|c|c|c|c|c|c|}
\hline \multirow{2}{*}{ Adsorbent } & \multirow[b]{2}{*}{ Conc $(\mathrm{mg} / \mathrm{L})$} & \multirow{3}{*}{$\begin{array}{r}\mathrm{q}_{\mathrm{e}} \\
\exp (\mathrm{mg} / \mathrm{g})\end{array}$} & \multicolumn{3}{|c|}{ pseudo-first-order } & \multicolumn{3}{|c|}{ pseudo-second-order } \\
\hline & & & $\mathrm{k}_{1}$ & $\mathrm{q}_{\mathrm{e} 1}$ & $\mathrm{R}^{2}$ & $\mathrm{k}_{2}$ & $\mathrm{q}_{\mathrm{e} 2}$ & $\mathrm{R}^{2}$ \\
\hline & & & $\left(\min ^{-1}\right)$ & $\left(\mathrm{mg} \cdot \mathrm{g}^{-1}\right)$ & & $\left(\mathrm{mg} \cdot \mathrm{g}^{-1} \cdot \mathrm{min}^{-1}\right)$ & $\left(\mathrm{mg} \cdot \mathrm{g}^{-1}\right)$ & \\
\hline \multirow{5}{*}{ MNG } & 50 & 305.06 & 0.1131 & 130.62 & 0.7623 & 0.0034 & 312.5 & 0.9999 \\
\hline & 75 & 410.85 & 0.0995 & 249.63 & 0.9031 & 0.0012 & 416.67 & 0.9999 \\
\hline & 100 & 485.42 & 0.1029 & 310.74 & 0.9242 & 0.0009 & 500 & 1 \\
\hline & 125 & 509.39 & 0.0967 & 255.33 & 0.8205 & 0.0013 & 526.32 & 0.9998 \\
\hline & 150 & 538.09 & 0.0933 & 254.16 & 0.7714 & 0.0012 & 555.56 & 0.9998 \\
\hline
\end{tabular}

Table 4. Langmuir, Freundlich and Redlich-Peterson isotherm parameters for adsorption of SDBS onto MNG nanosheets. 


\begin{tabular}{lcccccccccc}
\hline Adsorbent & \multicolumn{3}{c}{ Langmuir } & \multicolumn{3}{c}{ Freundlich } & \multicolumn{4}{c}{$\mathrm{R}-\mathrm{P}$} \\
\hline \multirow{2}{*}{ MNG } & $\mathrm{q}_{\mathrm{m}}(\mathrm{mg} / \mathrm{g})$ & $\mathrm{b}(\mathrm{l} / \mathrm{g})$ & $\mathrm{R}^{2}$ & $\mathrm{~K}_{\mathrm{f}}$ & $\mathrm{n}$ & $\mathrm{R}^{2}$ & $\mathrm{k}_{\mathrm{RP}}$ & $\mathrm{a}_{\mathrm{RP}}$ & $\beta$ & $\mathrm{R}^{2}$ \\
\cline { 2 - 28 } & 555.55 & 0.0000063 & 0.9983 & 313.2808 & 7.68 & 0.9858 & 687 & 1.3394 & 1 & 0.9982 \\
\hline
\end{tabular}

Table 5. Thermodynamic parameters of SDBS adsorption on MNG at different temperatures

\begin{tabular}{ccrrrrr}
\hline Temperature $(\mathrm{K})$ & $\mathrm{K}_{\mathrm{d}}(\mathrm{L} / \mathrm{g})$ & $\Delta \mathrm{H}^{\mathrm{o}}(\mathrm{J} / \mathrm{mol})$ & $(\mathrm{J} / \mathrm{mol})^{\circ} \Delta \mathrm{S}$ & $\Delta \mathrm{G}$ & $(\mathrm{kJ} / \mathrm{mol})$ & $\mathrm{R}^{2}$ \\
\hline 288 & 3.68 & 59.08 & 234.12 & -67.40 & 0.9495 \\
298 & 4.13 & & & -69.74 & \\
308 & 4.89 & & & -72.09 & \\
318 & 6.034 & & & -74.43 & \\
\hline
\end{tabular}

Figures

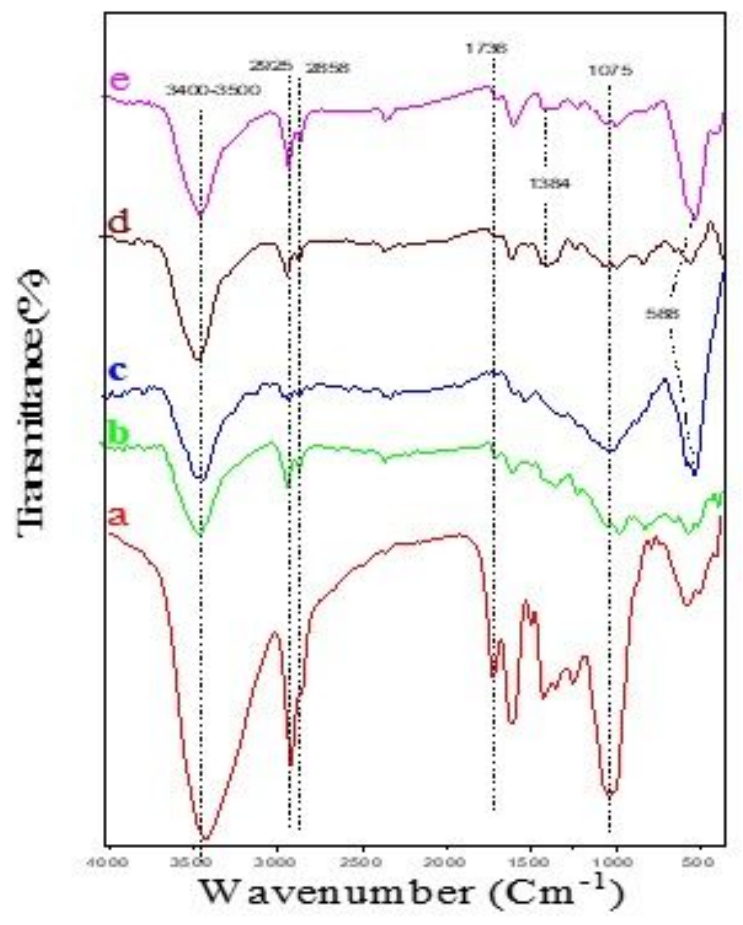

Figure 1

FTIR spectrum of (a) orange peel, (b) G, (c) MG, (d) NG, (e) and MNG 


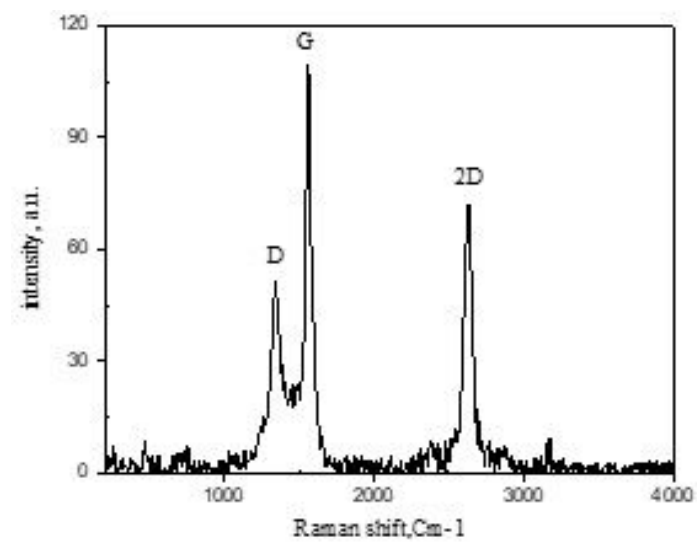

Figure 2

Raman spectroscopy of MNG nanosheet.
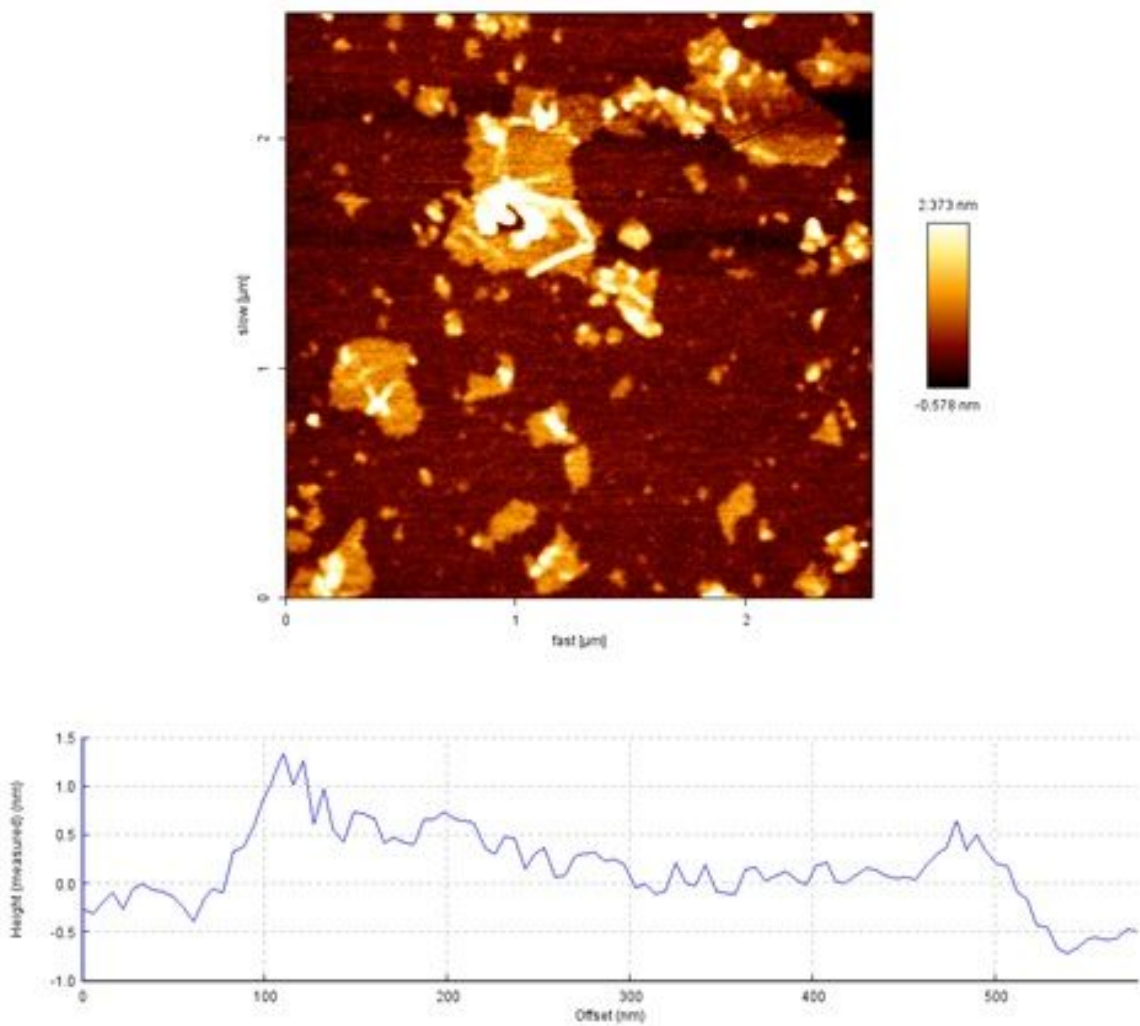

Figure 3

AFM images of MNG nanosheet. 


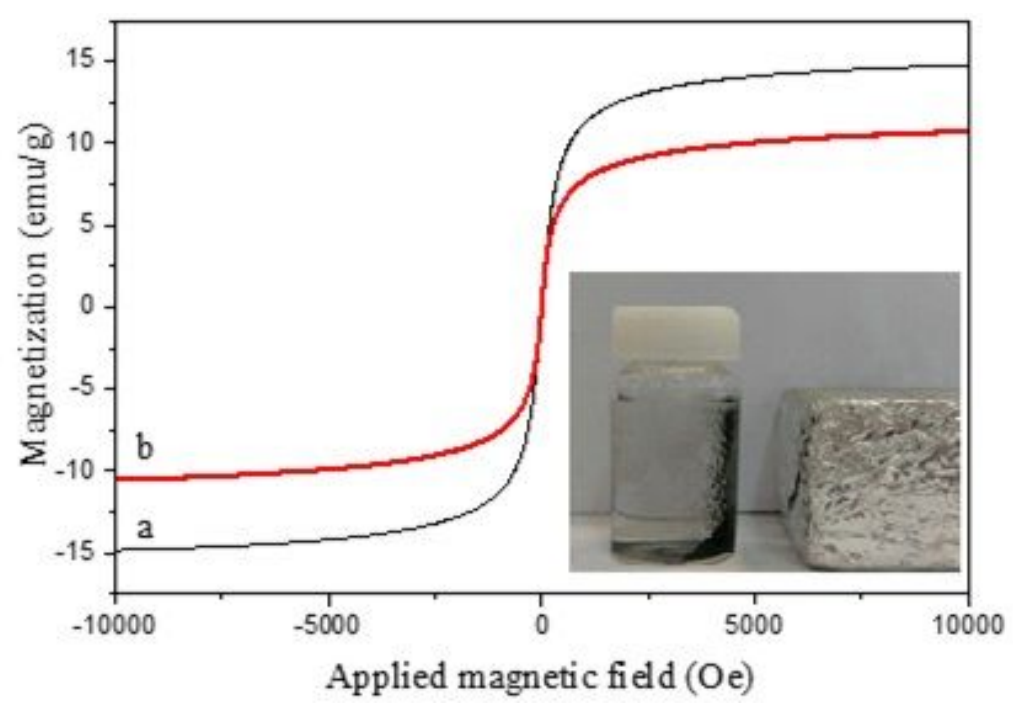

Figure 4

VSM curves of (a) MG and (b) MNG.
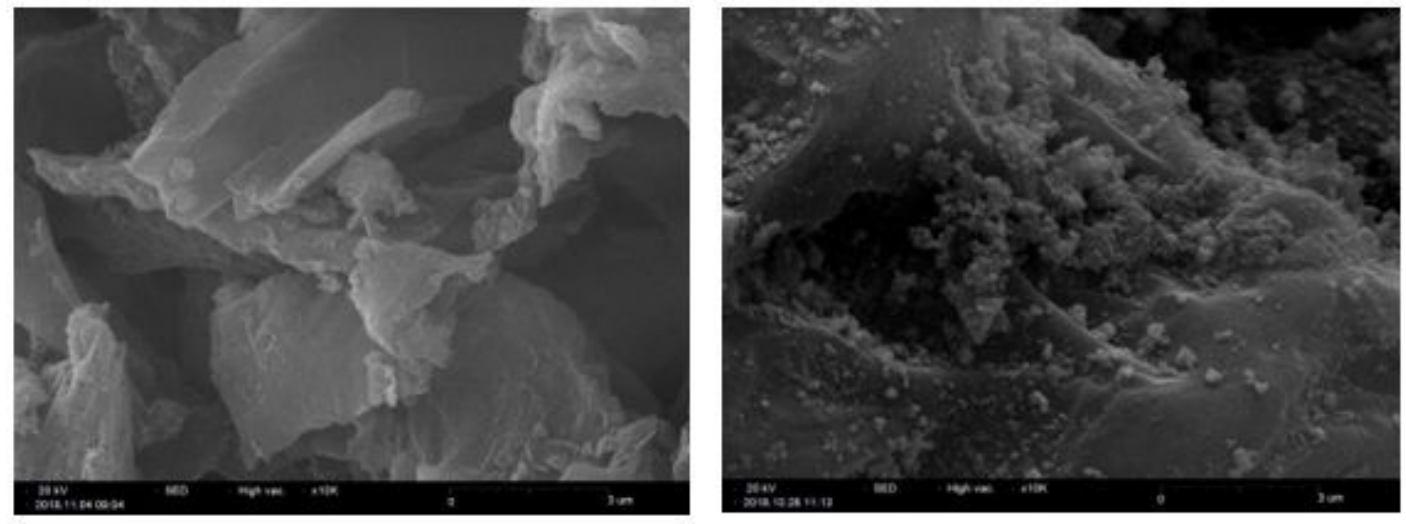

(a)

(b)

Figure 5

SEM images of (a) G and (b) MNG.

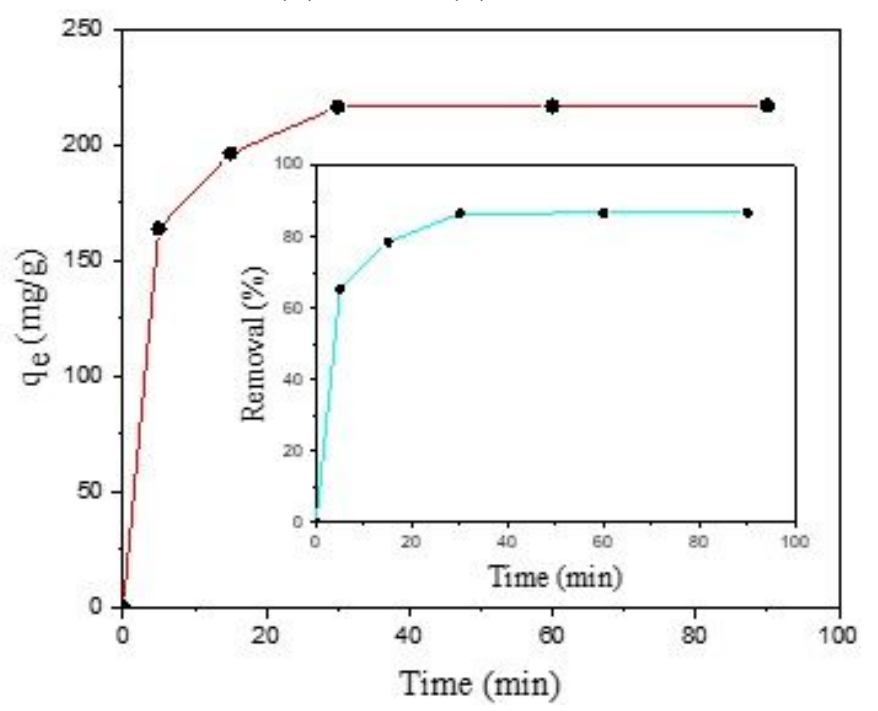

Figure 6 
Effect of contact time on SDBS adsorption onto MNG at an initial concentration of $50 \mathrm{mg} / \mathrm{L}$ and $\mathrm{pH}$ value of 6.5.

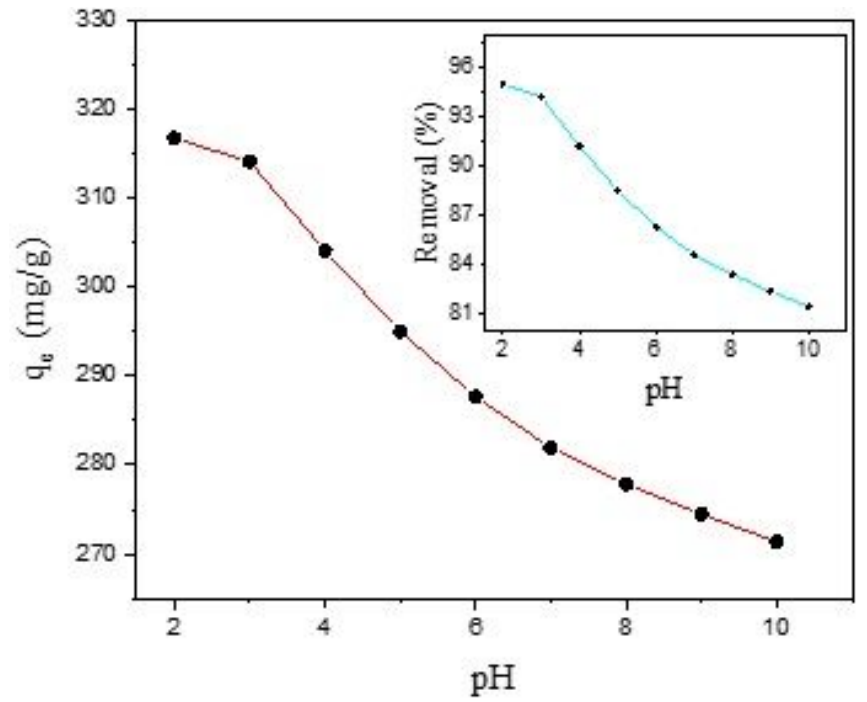

\section{Figure 7}

Effects of solution $\mathrm{pH}$ on adsorption of SDBS at adsorption dosage of $15 \mathrm{mg}$, initial concentration of $50 \mathrm{mg} / \mathrm{L}$ and contact time of $30 \mathrm{~min}$.

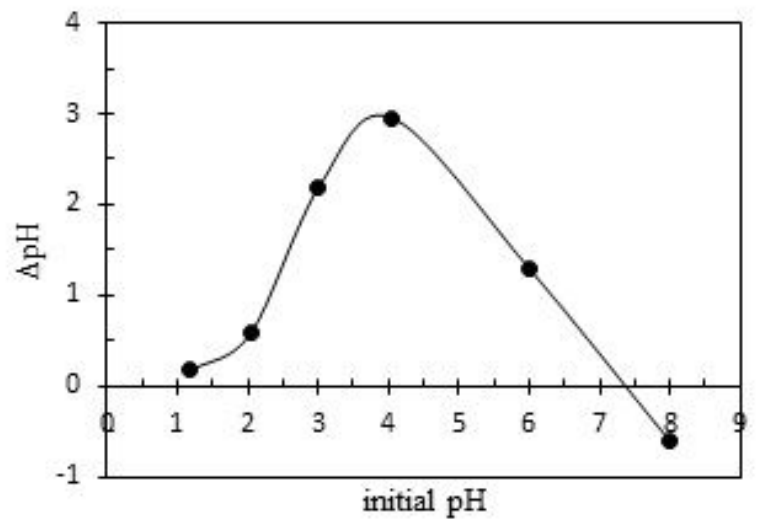

Figure 8

pHpzc of MNG. 


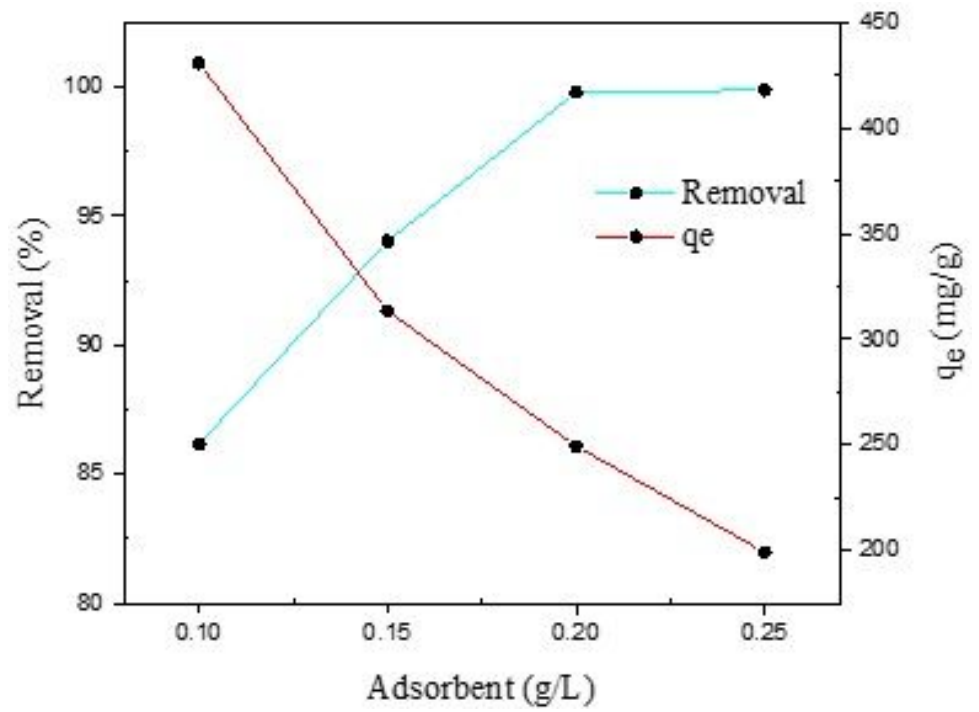

Figure 9

Effects of different adsorbent dosages on SDBS removal by MNG at pH value of 3 and contact time of 30 min.

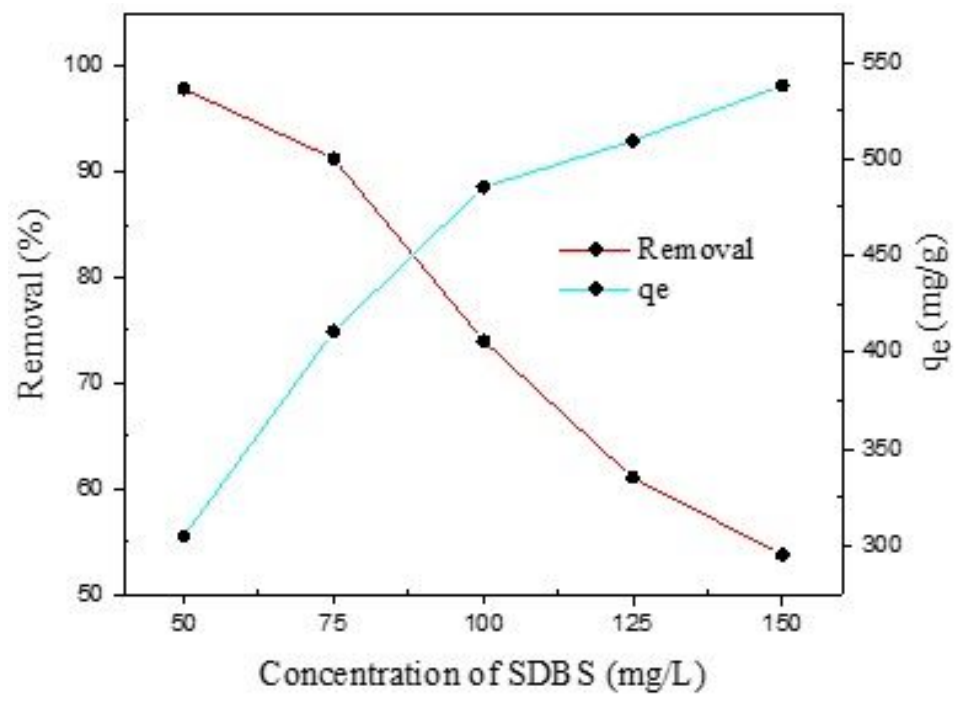

Figure 10

Effect of initial concentration of SDBS on adsorption removal and capacity at adsorbent dosage of $15 \mathrm{mg}$, contact time of $30 \mathrm{~min}$ and $\mathrm{pH}$ value of 3 . 


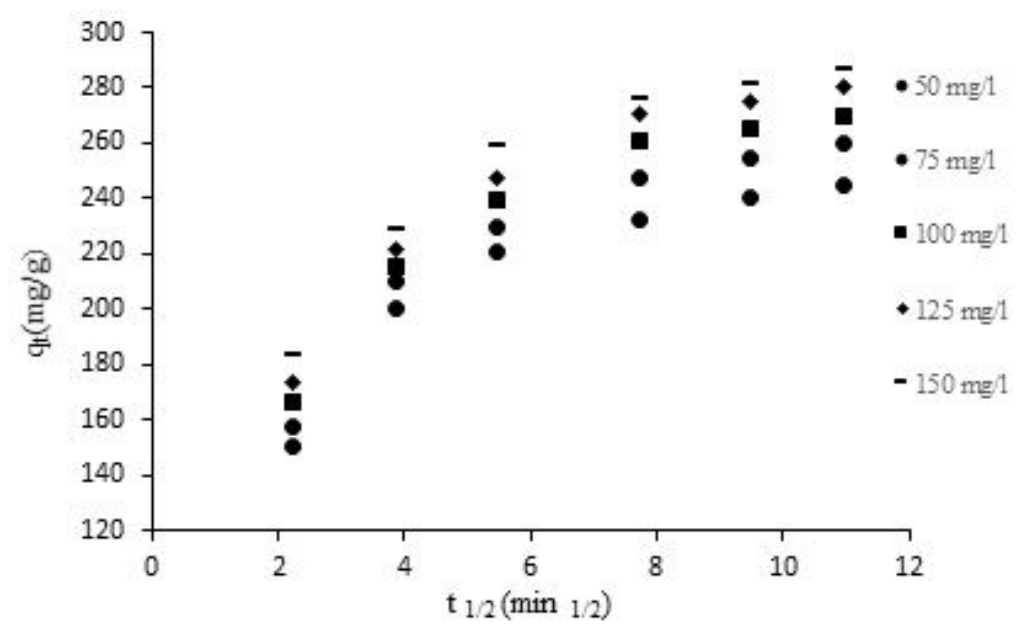

Figure 11

Kinetic models of intra particle diffusion for the adsorption of SDBS onto MNG. 

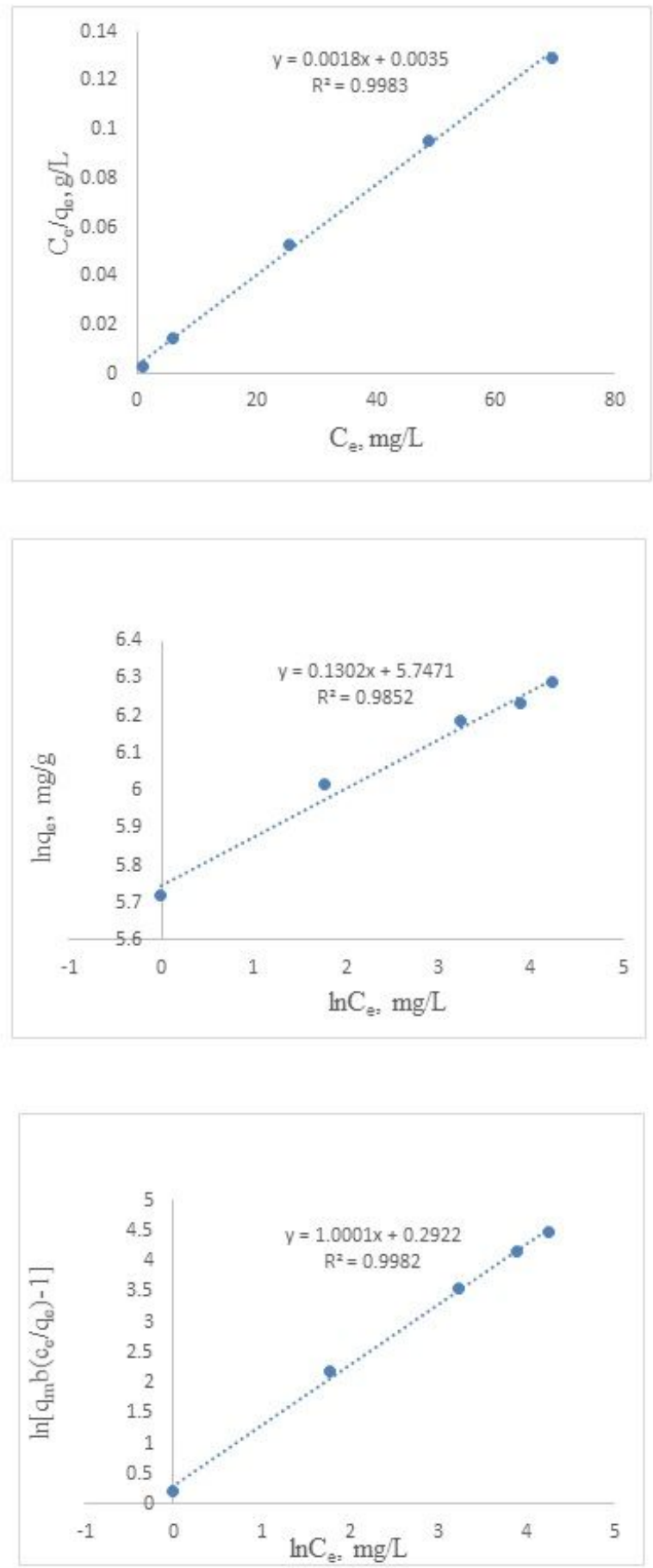

Figure 12

The equilibrium isotherm trends for SDBS onto MNG; (a) Langmuir, (b) Freundlich, (c) Redlich-Peterson. 


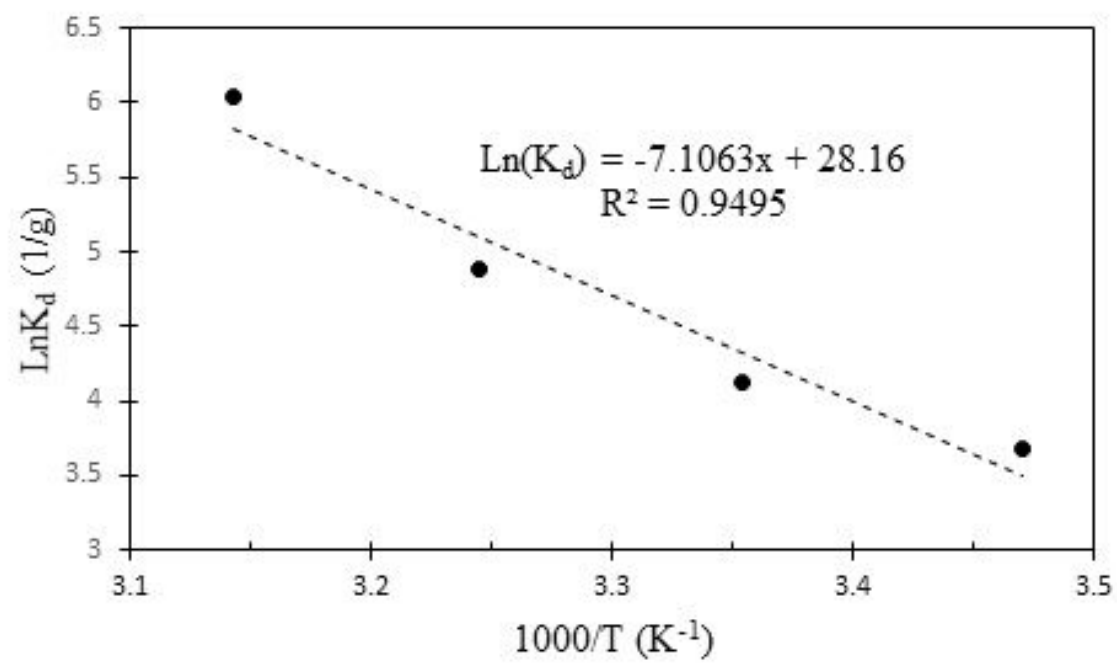

Figure 13

The Van't Hoff equation of SDBS adsorption onto MNG nanosheets.

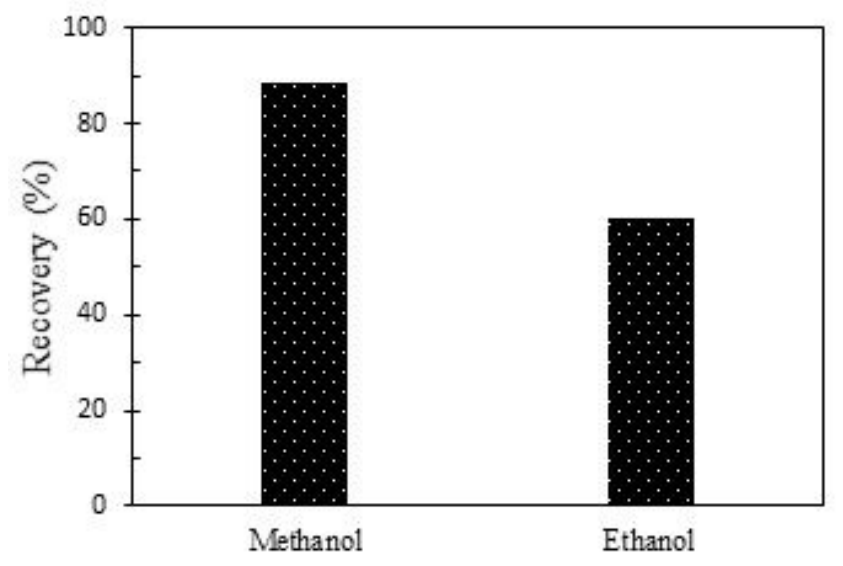

Figure 14

Effect of solvent type on the desorption of SDBS from MNG nanosheets.

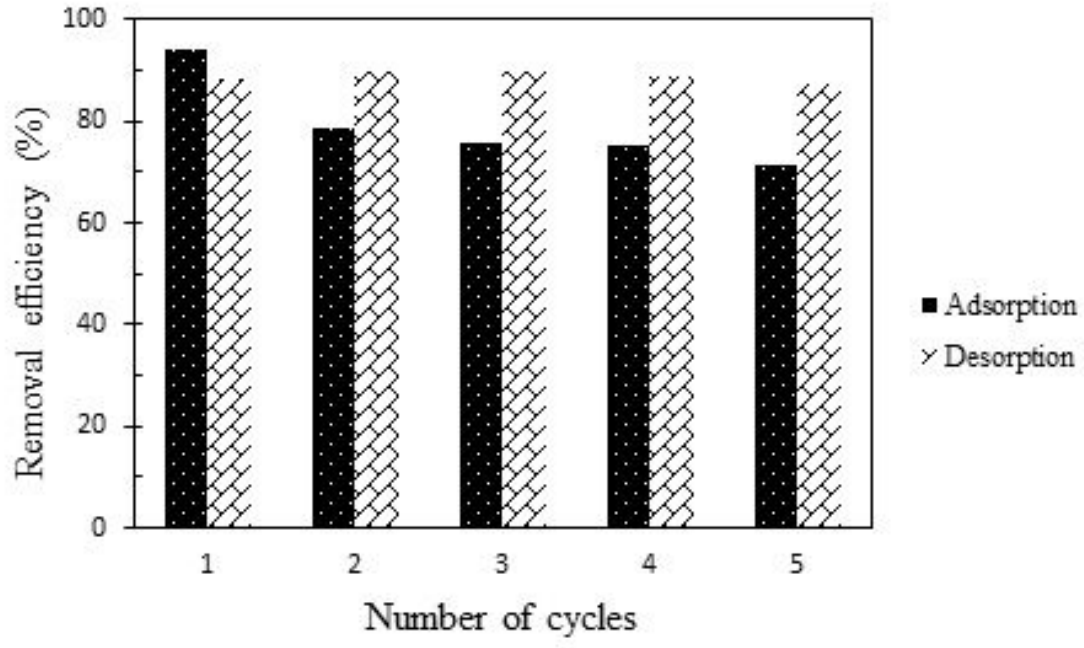

Figure 15 
The adsorption-desorption cycles of SDBS on MNG nanosheets.

Page 26/26 